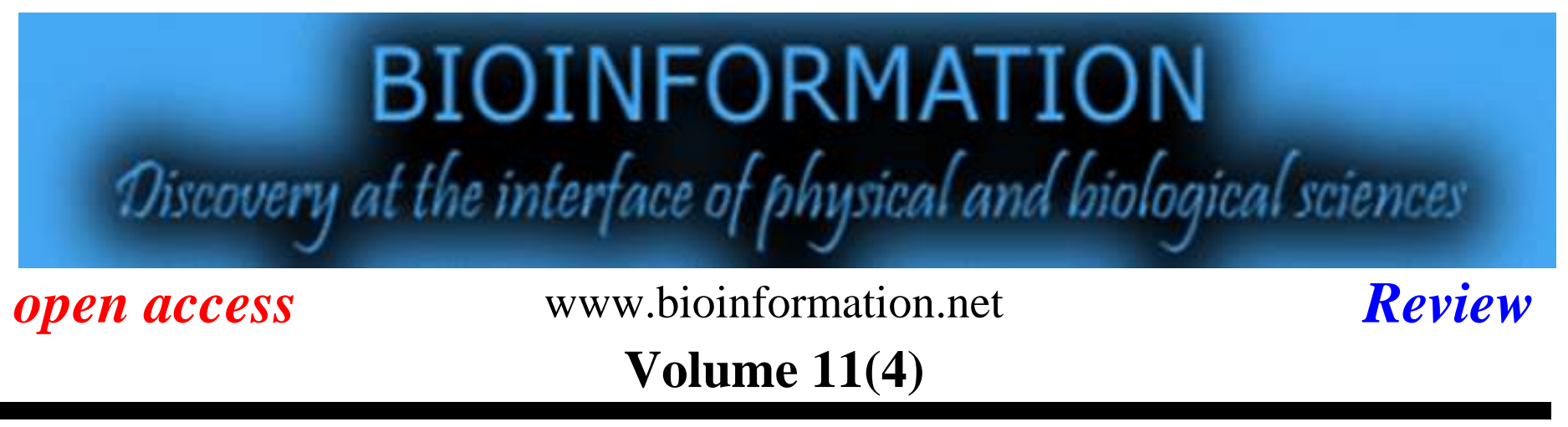

\title{
Chemosensory apparatus of Drosophila larvae
}

\author{
Chandra Bose†, Srijoni Basu†, Nabajit Das \& Sukant Khurana*
}

Indian Institute of Science Education and Research Kolkata (IISER-K), Mohanpur, West Bengal - 741246, India; Sukant Khurana - Email: sukantkhurana@gmail.com; *Corresponding author

†- Authors equally contributed

Received February 06, 2015; Accepted February 26, 2015; Published April 30, 2015

\begin{abstract}
:
Many insects, including Drosophila melanogaster, have a rich repertoire of olfactory behavior. Combination of robust behavioral assays, physiological and molecular tools render D. melanogaster as highly suitable system for olfactory studies. The small number of neurons in the olfactory system of fruit flies, especially the number of sensory neurons in the larval stage, makes the exploration of sensory coding at all stages of its nervous system a potentially tractable goal, which is not possible in the foreseeable future in any mammalian preparation. Advances in physiological recordings, olfactory signaling and detailed analysis of behavior, can place larvae in a position to ask previously unanswerable questions.
\end{abstract}

Keywords: Drosophila, olfaction, antenna, insects, mushroom body, antennal lobe, sensilla, olfactory receptors, odor-binding proteins.

\section{Background:}

Insects are one of the best examples of micro-miniaturization. The number of neurons involved in the olfactory processing for most species of insect varies between $10^{2}$ and $10^{5}$ [1], which is multiple order of magnitudes fewer than that in the smallest of mammals. The numerical simplicity of the olfactory system of insect might allow an in depth circuitry, cellular and overall computation analysis involved in sensory processing. Given the rich history of Drosophila melanogaster research and the availability of the plethora of experimental tools, it is one of the best systems to study genetics, behavior, molecular signaling, and epigenetics. Apart from all the benefits of studying adult Drosophila that also hold true for larval stage, the latter has the added advantage of smaller number of sensory neurons than adults. Larvae also have a translucent body wall, which might make neural imaging more tractable, if the issues of instability of larval preparation due to peristaltic motion can be completely overcome.

Many species in the animal kingdom rely heavily on detection and response to air-borne volatile chemicals, i.e., odorants, to assess features of environment such as food sources, ISSN 0973-2063 (online) 0973-8894 (print)

Bioinformation 11(4): 185-188 (2015) conspecifics, and predators, etc. As a result of this, many species have evolved a sensitive and selective olfactory apparatus. Correspondingly, a significant amount of the nervous system is devoted to process and extract information from this sensory modality. Hence, the olfactory system is an excellent platform for studying information coding, pattern detection, pattern separation, learning and memory, sensory representation and sensory processing. Given the numerical simplicity of the insect nervous system they offer significant advantages over many other organisms for researchers who wish to study the olfactory system.

Although olfactory receptors show a high divergence in insects and mammals [2], many second-messenger signaling pathways involved in the sensory processing are conserved $[3,4]$. Interestingly, many computational modules in the insect olfactory system appear to be similar to those in mammals, as might be the case for the reported similarities between glomeruli in olfactory bulbs of mammals and antennal lobes of adult Drosophila melanogaster. Apart from the applicability to mammals, it is a reward in itself to learn about insects, the most diverse members of animal kingdom. Diptera, i.e., flies, 
constitute 10 to $15 \%$ of all known animal species. We expect that many computational modules in insects would lead to efficient biology-inspired machines.

Although its use in olfactory studies precedes the development of genetic and molecular tools [5-7], Drosophila melanogaster has become a favored insect model organism for studying olfaction after the onset of molecular biology revolution. Seymour Benzer's group first started with the neurogenetic analysis of Drosophila melanogaster, opening a vastly enriching avenue of neuroscience. Obaid Siddiqi at the height of success in bacterial and fungal genetics chose to change the direction of his scientific research to join Benzer's burgeoning group and start Drosophila neurophysiology. After returning back from Benzer's lab, Obaid turned to the sense of smell and his lab opened up the new field of chemosensory genetics [8-12]. Members of Benzer's lab, especially William G Quinn, went forward to explore olfactory learning with equal zeal, now making Drosophila olfactory conditioning one of the most popular models for learning and memory studies. This enterprise has resulted in a plethora of molecular and genetic information, with mutants in olfactory signaling and olfactory conditioning pathway continuously added to the list. However, systems level understanding of the olfactory computation is still relatively missing. Only in a small nervous system, can one image the whole neural network, instead of focusing on a small component microcircuit. We suspect that the translucence of the larval stage potentially offers the added advantage of imaging the nervous system without dissection. Increasing efforts on the epigenomic and metabolomic studies using fruit flies can make larvae as the pioneering system for a comprehensive understanding of the olfactory information processing. Before we review literature on larval olfaction, we briefly describe the olfactory apparatus of adult Drosophila for dual purpose of comparative analysis of the adult and larval stage and also to provide a placeholder until certain information becomes available for the larval stage.

\section{Olfactory system in the adult Drosophila:}

Olfactory recognition in the adult Drosophila melanogaster is accomplished by sensory hairs called sensilla, distributed over the surface of the third antennal segment and maxillary palp. There are four types of sensilla on antenna namely sensilla basoconica, sensilla coeloconica and sensilla trichoidia [10, 13] and an intermediate one with properties of both trichoid and basoconic sensilla [14].

Different sensillae respond to different set of odorants $[10,15-$ 18]. Each sensillum has 1 to 4 neurons. Olfactory neurons expressing a given olfactory receptor gene within sensory hairs sends projections to one or two of the loci $[2,19-22]$, known as glomeruli, within the antennal lobe of the insect brain. The majority (five-sixths) of olfactory neurons sends axons that branch and innervate both the ipsilateral and contralateral antennal lobes; the remaining neurons project only ipsilaterally [23]. The glomeruli are innervated by dendrites of projection neurons, which in turn project to the protocerebrum. Another site for olfactory reception is maxillary palp. It extends from the proboscis and contains only 120 olfactory receptor neurons (ORNs), housed in 60 sensilla basiconica [15, 24]. Projections from the maxillary palp reach antennal lobe through the labiomaxillary nerve.
The adult protocerebrum includes the mushroom bodies (MB), the central complex (CX), the pars intercerebralis, and the optic lobes. The CX function is likely related to an integration of information from the right and left halves of the brain, multisensory integration and to the global control of fly walking activity including speed and straightness [25-32]. The $\mathrm{MB}$ and $\mathrm{CX}$ structures and their function are well conserved throughout the insect kingdom. Exploration of involvement of protocerebrum in the olfactory responses and olfactory conditioning responses has been the subject of many studies especially, conditioning studies, with most attention focused on mushroom bodies. In insects, mushroom bodies play an important role in the associative learning of olfactory information [1, 33]. The MBs of Drosophila melanogaster comprise of about 2500 neurons per brain hemisphere. The cell bodies of these neurons are situated in the dorsal posterior brain region and extend axons bundles together to form peduncle and then give rise to the alpha/beta, alpha'and gamma lobes of $\mathrm{MB}$. These lobes are neuropile regions that contain the $\mathrm{MB}$ cell axons and other processes that synapse with MB neurons.

\section{Olfactory system in the larvae:}

The chemosensory apparatus of the larval head is formed during late embryogenesis [2, 34]. Each of the two dorsal organs (DO) contains 21 olfactory neurons. Previous morphological and cytoarchitectural work, have helped in the determination of the olfactory function of DO and it has been supported by data obtained from toxin inactivation and electrophysiological studies [3, 4, 35, 36]. The dorsal organ remains connected to the larval antennal lobe (LAL) by antennal nerve (AN). The antennal nerve has projections from 21 dorsal organ neurons and 12 gustatory projections from DO and Terminal Organ (TO). The AN is also joined by an entirely gustatory labral nerve. This compound nerve bifurcates to project to the midline of tritocerebral identity of LAL and CNS. Another maxillary nerve with purely gustatory projections does not fuse with antennal-labral nerve. Some of the details of olfactory and gustatory projection are yet unknown and it will be very useful to explore whether the close association of gustatory and olfactory projections in larvae has any physiological and behavioral significance.

LAL is not bigger than a single glomerulus of the adult lobe [5$7,37]$ and has been reported to consist of structural subunits [812, 38]. The input and output fibers have been found to be associated with the subunits of the LAL rather than with its entire neuropil. It raises the possibility that LAL may be organized in a somewhat similar way to the adult AL. The total number of subunits have been estimated and is found to be approximately 30 , a smaller number than adult [10, 13, 37, 39]. Their average size of 5 to 10 micrometer diameter is only approximately one fifth of that of an adult glomerulus. This raises ultrastructural questions whether these structures are composed of multisynaptic contact zones considered typical of glomerular organization. In holometabolous insects, adult glomeruli form de novo, from an aglomerular neuropil [14, 37, 39]. Hence, there is no direct correlation between larval subunits and adult glomeruli.

The larva possesses a miniature form of mushroom body (MB). One Drosophila mushroom body is derived from four 
indistinguishable cell lineages, development of which involves sequential generation of multiple distinct types of neurons [10, 15-18, 40]. A small dendritic domain in the adult MB calyx remains as a fourfold structure, which is similar to the entire larval calyx and receives dendritic inputs from all four $\mathrm{MB}$ clones $[2,19-22,40]$.

The flow of information shows divergence at the level of projection from the dorsal organ to the larval antennal lobe and from the larval antennal lobe to the mushroom body. At the level of projection from sensilla to larval antennal lobe, the principles of sensory coding seem to be very different than that of adult, where information from thousands of sensilla converge on 43 glomeruli. The sizes of the glomeruli in larvae are much smaller than adults, possibly reflecting smaller number of synapses involved. It is not obvious how the larvae have rich repertoire of olfactory responses [11, 23, 41, 42] despite having only 21 olfactory neurons in the dorsal organ. Thus, recoding from the olfactory neurons may hold a great potential of studying the temporal pattern of action potentials at sensory periphery.

Although the first two instars of larvae have been examined by a few researchers, a detailed characterization of the differences in larval olfactory abilities as a function of development is currently missing. This can be a valuable tool to assess the role of different structures in olfactory responses, discrimination and conditioning. Towards the end of third instar, the larvae start exhibiting a negative geotactic response and move out to the surface of media to pupate. What is the role of olfaction in fruit fly with regard to such kind of responses still remains to be assessed. Given that larvae have far less number of neurons than adult fruit fly, understanding of the coding of odorants and mixtures at periphery and transformation of this code at multiple levels of sensory processing is going to be easier in larvae than adult fly. Many other systems like C. elegans offer a similar simplicity of anatomical organization but it is not known whether other simple systems have the richness of olfactory response repertoire as D. melanogaster larvae.

\section{Olfactory Signal transduction:}

Majority of information on olfactory signaling comes from studies in the adult stage. Limited studies in the larval stage suggest overwhelming similarities across the two developmental stages. Unless otherwise stated the following information comes from studies on adult Drosophila. Odors must reach the dendrites of olfactory receptor neurons in order to convey the olfactory message, where the G-protein coupled olfactory receptors are located. This step is speculated to be protein-assisted given that dendrites, which are surrounded by sensillar lymph and odors are largely hydrophobic in nature. Odorant binding proteins, (OBPs) of unknown function are present at high concentration in the sensillar lymph. These proteins may solubilize hydrophobic odorants in the aqueous sensillum lymph, present these odorous ligands to the receptor or assist in terminating the odor response by removing ligands from the receptor [15, 24, 43-45]. Possibility of OBPs in direct odor recognition has been suggested [25-32, 46, 47] as they are present in small subdomains of antenna. The first functional evidence that OBPs indeed participate in olfactory responses comes from the analysis of Drosophila mutants that lack the LUSH OBP $[46,47]$ and fail to respond to ethanol.
In diverse species, a large family of odorant receptor genes, each encoding a different seven-transmembrane domain $G$ protein-coupled receptor, mediates molecular recognition of thousands of distinct odorants. The first candidate odorant receptor genes were identified in the rat by a degenerate polymerase chain reaction approach using primers capable of identifying members of the $G$ protein-coupled receptor superfamily [48]. Subsequently, several odorant receptor genes have been identified in other mammals, fish and birds using homology-based approaches with rat sequences used as a reference point.

Candidate Drosophila olfactory receptor (DOR) genes were identified by a combination of difference cloning [20] and analysis of Drosophila genomic sequence databases $[2,20,49]$. The completion of the Drosophila genome sequence has permitted an analysis of the complete repertoire of DOR genes. The fly genome has a total of 60 genes with homology to the DOR gene family [2, 20, 49]. Although these genes are extremely divergent, sharing on average only $20 \%$ amino acid identity, conserved sequences in the putative seventh transmembrane domain are a signature of this family and are found in all 60 DOR genes.

Action potential generated by olfactory receptor neurons (ORN) in response to odorants travels down to antennal lobe. The coding of odor quality and quantity may be in the form of a spatial map or a temporal code or a combination of both. Calcium imaging measurements made on mushroom body neurons revealed that the activity pattern of an odor induced population response is specific for the chemical identity of an odorant and its concentration [50]. Increasing the concentration of an odor did not increase activation of one area or increase the area being activated. It was found to change the distribution of activation [50]. An interesting indication in this study was that different flies have different activity patterns for different odors, while in the same animal the pattern for the same odor was similar after different trials [50].

In recent years, expanding work on behavioral, genetic and neurophysiological studies on larval olfaction and application of olfactory assays to other fields, such as alcoholism, learning and memory [11, 12, 42, 51-66] suggest a very bright future of studies on this model system.

\section{Conclusion:}

Drosophila olfaction is an expanding field with an opportunity to understand a sensory modality, integrating behavioral, molecular and physiological approaches. This system may present the first opportunity of a comprehensive understanding of the sensory coding, its transformation at each successful level and finally the motor output.

\section{References:}

[1] Ache BW, Semin Cell Biol. 1994 5: 55 [PMID: 8186396]

[2] Gao Q \& Chess A, Genomics 1999 60: 31 [PMID: 10458908]

[3] Yoshihara M et al. Funct Integr Genomics. 2001 1: 235 [PMID: 11793242]

[4] Bargmann CI, Science 1998 282: 2028 [PMID: 9851919]

[5] Barrows WM, J Exp Zool. 1907 4: 515

[6] Begg M \& Hogben L, Proc R Soc Med. 1946 133: 1 [PMID: 21014288] 
[7] Reed MR, Physiological Zoology 1938 11: 317

[8] Siddiqi O \& Benzer S, Proc Natl Acad Sci USA. 1976 73: 3253 [PMID: 184469]

[9] Rodrigues V \& Siddiqi O, Mol Gen Genet. 1981 181: 406 [PMID: 6787393]

[10] Siddiqi O, Trends in Genetics 1987 3: 137

[11] Khurana S \& Siddiqi O, Chem Senses. 2013 38: 315 [PMID: 23363465]

[12] Khurana S et al. J Biosci. 2009 34: 621 [PMID: 19920347]

[13] Venkatesh S \& Singh RN, International Journal of Insect Morphology and Embryology 1984 13: 51

[14] Shanbhag SR et al. International Journal of Insect Morphology and Embryology 1999 28: 377

[15] de Bruyne M et al. J Neurosci. 1999 19: 4520 [PMID: 10341252]

[16] de Bruyne $M$ et al. Neuron 2001 30: 537 [PMID: 11395013]

[17] Yao CA et al. J Neurosci. 2005 25: 8359 [PMID: 16162917]

[18] Clyne P et al. Invert Neurosci. 1997 3: 127 [PMID: 9783438]

[19] Stocker RF, Cell Tissue Res. 1994 275: 3 [PMID: 8118845]

[20] Vosshall LB et al. Cell 1999 96: 725 [PMID: 10089887]

[21] Vosshall LB et al. Cell 2000 102: 147 [PMID: 10943836]

[22] Vosshall LB et al. Curr Opin Neurobiol. 2000 10: 498 [PMID: 10981620]

[23] Stocker RF et al. Cell Tissue Res. 1990 262: 9 [PMID: 2124174]

[24] Singh RN \& Nayak SV, International Journal of Insect Morphology and Embryology 1985 14: 291

[25] Solanki N et al. J Neurogenet. 2015 29: 30 [PMID: 25585638]

[26] Weir PT et al. J Neurophysiol. 2014 111: 62 [PMID: 24108792]

[27] Sakai T \& Kitamoto T, J Neurobiol. 2006 66: 821 [PMID: 16673386]

[28] Seelig JD \& Jayaraman V, Nature 2013 503: 262 [PMID: 24107996]

[29] Hanesch U et al. Cell Tissue Res. 1989 257: 343

[30] Ilius M et al. J Neurogenet. 2007 21: 321 [PMID: 18161592]

[31] Barth M \& Heisenberg M, Learning \& Memory 1997 4: 219 [PMID: 10456065]

[32] Bausenwein B \& Müller N, J Com Neurol. 1994 340: 255 [PMID: 8201021]

[33] de Belle JS \& Heisenberg M, Science 1994 263: 692 [PMID: 8303280]

[34] Frederick RD \& Denell RE, International Journal of Insect Morphology and Embryology 1982 11: 227

[35] Heimbeck G et al. J Neurosci. 1999 19: 6599 [PMID: 10414987]

[36] Tissot M et al. J Neurobiol. 1997 32: 281 [PMID:9058321]
[37] Python F \& Stocker RF, J Comp Neurol. 2002 445: 374 [PMID: 11920714]

[38] Ramaekers A et al. Curr Biol. 2005 15: 982 [PMID: 15936268]

[39] Zhu S et al. Development 2003 130: 2603 [PMID:12736205]

[40] Gerber B \& Stocker RF, Chem Senses. 2007 32: 65 [PMID: 19145411]

[41] Gerber B et al. Results Probl Cell Differ. 2009 47: 139 [PMID: 19145411]

[42] Vogt RG et al. J Exp Biol. 2002 205: 719

[43] Hekmat-Scafe DS et al. J Neurosci. 1997 17: 1616 [PMID: 9030621]

[44] Park SK et al. Cell Tissue Res. 2000 300: 181

[45] Kim MS et al. Genetics 1998 150: 711 [PMID: 9755202]

[46] Kim MS \& Smith DP, Chem Senses. 2001 26: 195 [PMID: 11238251]

[47] Buck L \& Axel R, Cell 1991 65: 175 [PMID: 1840504]

[48] Clyne PJ et al. Neuron 1999 22: 327 [PMID: 10069338]

[49] Wang F et al. Cell 1998 93: 47 [PMID: 9546391]

[50] Chen YC \& Gerber B, J Exp Biol. 2014 217: 2071 [PMID: 24920835]

[51] Saumweber T et al. Biol Open. 2014 3: 1005 [PMID:25260919]

[52] Niewalda T et al. Biol Open. 2014 3: 575 [PMID: 24907371]

[53] Khurana S et al. PLoS ONE 2010 5: e15259 [PMID: 21209929]

[54] Khurana S et al. Behav Genet. 2012 42: 151 [PMID: 21833772]

[55] Robinson BG et al. PLoS ONE 2012 7: e37394 [PMID: 22624024]

[56] Robinson BG et al. Commun Integr Biol. 2013 6: e23501 [PMID: 23750304]

[57] Robinson BG et al. Curr Biol. 2012 22: 2338 [PMID: 23200990]

[58] Farine JP et al. Proc Biol Sci. 2014 281: 20140043 [PMID: 24741012]

[59] Ohashi S et al. Neurosci Lett. 2014 570: 10 [PMID: 24747684]

[60] Grewal JS et al. Biol Open. 2014 3: 947 [PMID: 25238759]

[61] Apostolopoulou AA et al. Front Behav Neurosci. 2014 8: 11 [PMID: 24478658]

[62] Gomez-Marin A \& Louis M, Front Behav Neurosci. 2014 8: 38 [PMID: 24592220]

[63] Gomez-Marin A et al. Nat Commun. 2011 2: 441 [PMID: 21863008]

[64] Gomez-Marin A et al. PLoS ONE 2012 7: e41642 [PMID: 22912674]

[65] Fishilevich E et al. Curr Biol. 2005 15: 2086 [PMID: 16332533]

[66] Wang Y et al. Cell Rep. 2013 3: 820 [PMID: 23453968]

Edited by $P$ Kangueane

Citation: Bose et al. Bioinformation 11(4): 185-188 (2015)

License statement: This is an open-access article, which permits unrestricted use, distribution, and reproduction in any medium, for non-commercial purposes, provided the original author and source are credited 